\title{
Modelling and optimization of a natural gas supply system at a transient stage: a case study of China
}

\author{
Tianxiao Li, Pei Liu* and Zheng Li
}

\begin{abstract}
The global energy structure is on a low-carbon transition path featuring more natural gas consumption, and global natural gas demand has been increasing fast. Planning and operation of a natural gas supply system at a transient stage with multiple supply sources, end-consumers, and large infrastructure with multiple sub-systems are challenging tasks. Spatial and seasonal mismatch of natural gas supply and demand makes the natural gas distribution and infrastructure construction planning problem even more complex. Without proper planning, insufficient construction could lead to a shortage of natural gas supply, whilst excessive construction could lead to a higher cost. Quantitative analysis technologies are needed to facilitate decision-making during the transient stage of a natural gas system. In this work, we propose a monthly-scale multi-period and multi-regional modelling and optimization framework for planning and operation of a natural gas supply system at a transient stage, with a case study of the natural gas supply system in China. The optimal planning and operation strategy of the natural gas supply system in China by 2050 is obtained by minimizing the lifespan overall cost. Gaps between actual planning and the optimal planning are pointed out. Finally, policy suggestions are summarized, including establishing market-oriented pricing mechanisms, managing infrastructure centrally, promoting coordination amongst provinces when formulating projections, accelerating current infrastructure construction, and predicting natural gas demand and prices reasonably.
\end{abstract}

Keywords: Natural gas, Supply system, Modelling, Optimization, Transient stage

\section{Background}

In recent years, global natural gas consumption has grown rapidly, and the share of natural gas in primary energy consumption has reached a historical high level of $23.4 \%$. In 2017 , global natural gas consumption increased by $3 \%$, higher than the overall energy consumption growth rate of $2.2 \%$. The increase is mainly from China, the Middle East and Europe, accounting for $15.1,13.6$, and $12.7 \%$, respectively [1].

Natural gas supply highly depends on specialized and high-cost infrastructure, including pipeline networks, liquid natural gas (LNG) ports, and storage facilities. Spatial mismatch between natural gas resources and natural gas demand requires a large amount of infrastructure. In 2017, international natural gas trade reached

\footnotetext{
*Correspondence: liu_pei@tsinghua.edu.cn

State Key Lab of Power Systems, Department of Energy and Power

Engineering, Tsinghua-BP Clean Energy Center, Tsinghua University, Beijing 100084, China
}

1134 billion cubic meters (bcm), accounting for $31 \%$ of global natural gas consumption, of which 740.7 and $393.4 \mathrm{bcm}$ were transmitted through pipelines and LNG ports, respectively [1].

The rapid growth of natural gas consumption is the inherent demand and external performance of low carbon transition. The low carbon transition requires more natural gas infrastructure, and infrastructure costs are a major part of the cost of natural gas supply systems. If infrastructure costs are too high, the low-carbon transition would slow down, break off or even reverse. Therefore, developing an appropriate planning framework to obtain the optimal planning, which is a timetable of the infrastructure expansion, by minimizing the overall cost would facilitate the transition.

Modelling and optimization of a natural gas supply system at a transient stage is a challenging work. The variety of space and time would greatly increase the 
uncertainty of a system, including multiple supply sources, end-users, subsystems, transmission and processing technologies. In addition, economic performance of technologies should also be considered.

Modelling and optimization of an energy supply system to solve spatial mismatch of energy supply and demand have been studied in many researches. A spatial heating model in Denmark was established to compare the energy supply cost between individual natural gas supply and district heating supply [2]. A spatial model with multiple energy supply and end-use technologies in UK was developed aiming at identifying a low-carbon transition pathway [3]. Shan et al. [4] assessed the reliability of a heating system by developing a heating distribution network model. Geothermal energy resource, georeferenced data of buildings and road networks were integrated into a district heating model, and optimal infrastructure construction plan was obtained by minimizing the construction cost [5]. Pan et al. [6] established a dynamic model of China's oil supply chain and simulated oil distribution to evaluate the energy security. Geographic Information System was applied to develop an urban energy system model and plan sustainable energy systems in cities [7]. Spatially modelling were widely applied in other energy systems, including power grid [8], power generation capacity [9] and considering carbon policy [10], distributed energy systems [11], bioenergy [12] and hydrogen [13].

Spatial modelling is also applied in researches on natural gas supply systems. Roger [14] reviewed and summarized modelling methods of natural gas pipeline components and optimization researches on natural gas gathering, transmission and distribution models. Dejan [15] developed a spatial natural gas distribution networks model based on improved Hardy Cross method [16]. Halit [17] established a nonlinear optimization model to obtain the optimal construction plan by minimizing investment and operation costs. Dieckhoner et al. [18] and Chaudry et al. [19] developed a pipeline network model and obtained an expansion plan to address increasing demand of natural gas based on existing infrastructure. An interconnected natural gas and electrical transmission model was developed for the natural gas system in Illinois, considering spatiotemporal changes in energy demand [20]. The supply reliability of pipeline networks was defined and assessed based on the infrastructure modelling [21], and applied in city [22] and country [23] level. Zhang et al. [24] established a multi-regional natural gas distribution model of China, and optimized gas flow and infrastructure deployment by minimizing the total supply cost.

However, previous studies focus mainly on spatial scales, whilst large disparities over space and time are still not well studied in natural gas supply systems, especially in a transient stage. Besides spatial mismatch, hourly, monthly and yearly changes on both supply and demand sides make the energy supply even more challenging. Yearly natural gas demand increases fast. Monthly demand fluctuates greatly because of significant heating demand in cold months, which is usually neglected in existing studies. Natural gas storage facilities play an important role to deal with seasonal fluctuations. Therefore, a natural gas supply system can be extremely complex in a large area and during a long period, because of spatial and seasonal mismatches between supply and demand.

The aforementioned problems with planning of a natural gas system are happening in China, and they could become increasingly more severe if not properly addressed. China is a large natural gas consumer, accounting for $5.9 \%$ of the world's natural gas consumption [25]. Natural gas has been identified as a transition energy from fossil fuels to renewable energy in China [26]. Natural gas consumption has increased by 57\% from 2012 to 2017 [27]. In 2017, China's natural gas consumption exceeded $237 \mathrm{bcm}$, ranking the third in with world [28].

China's natural gas demand is projected to keep the fast increasing momentum in the future. According to the 13th-five-year plan in China, natural gas demand is projected to further increase and account for $10 \%$ of total energy demand by 2020 [29]. Many studies have also attempted to predict future China's natural gas demand. Li et al. [30] developed a system dynamics model to forecast natural demand in China. Self-adapting Grey models [31], nonlinear Grey models [32] and Bayesian Model Averaging [33] were also applied to forecast natural gas demand. Shaikh and Ji [34] compared forecast results of different studies, and most researches indicated that China's natural gas demand would vary between 350 and $400 \mathrm{bcm}$ by 2020 .

The spatial mismatch of natural gas production and demand are significant in China [27], as shown in Figs. 1 and 2. A large number of cross-provincial pipeline networks and import facilities have been constructed and operated by three firms, namely Sinopec [35], CNPC [36] and CNOOC [37], as shown in Fig. 3. In the meanwhile, nation-wide seasonal fluctuations of natural gas demand are significant. Seasonal fluctuations in different regions are rather different, which make the management of China's natural gas supply system more complicated.

In this paper, a monthly-scale multi-period and multiregional modelling and optimization framework of a natural gas supply system at a transient stage is proposed. The natural gas supply system in China is applied as a case study, which exhibits the aforementioned features of complexity in terms of its rapid increase in demand, 


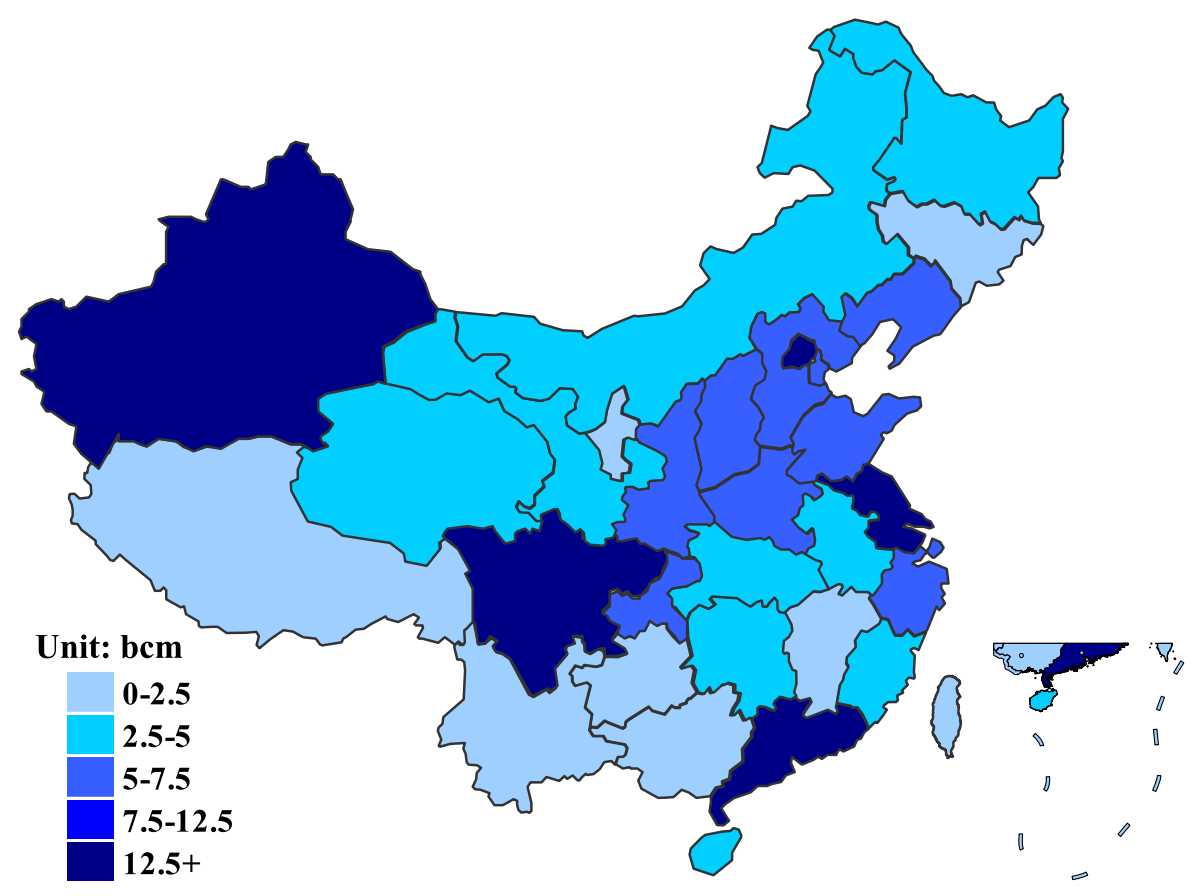

*The map is openly and freely accessed from the National Platform for Common Geospatial Information Services

Fig. 1 Natural gas production by province in 2016

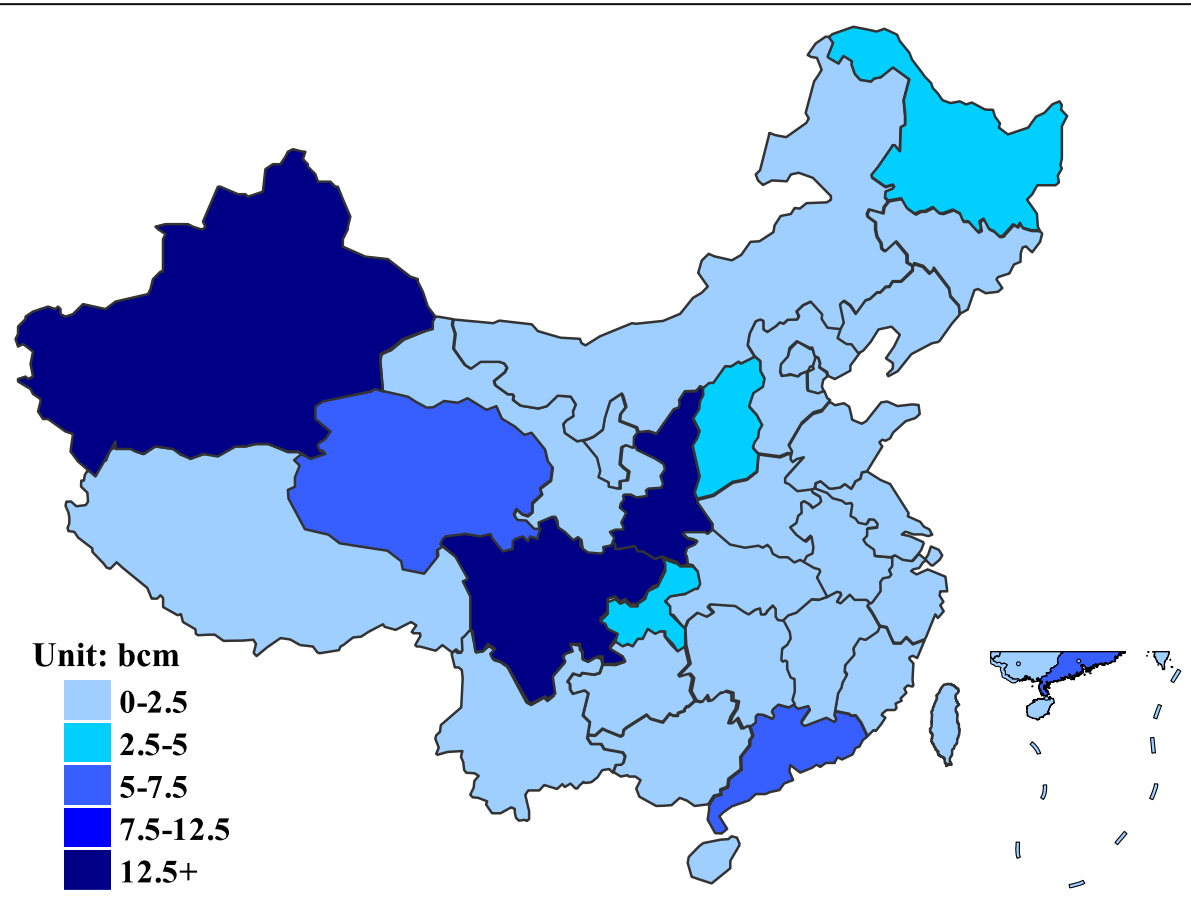

*The map is openly and freely accessed from the National Platform for Common Geospatial Information Services

Fig. 2 Natural gas consumption by province in 2016 


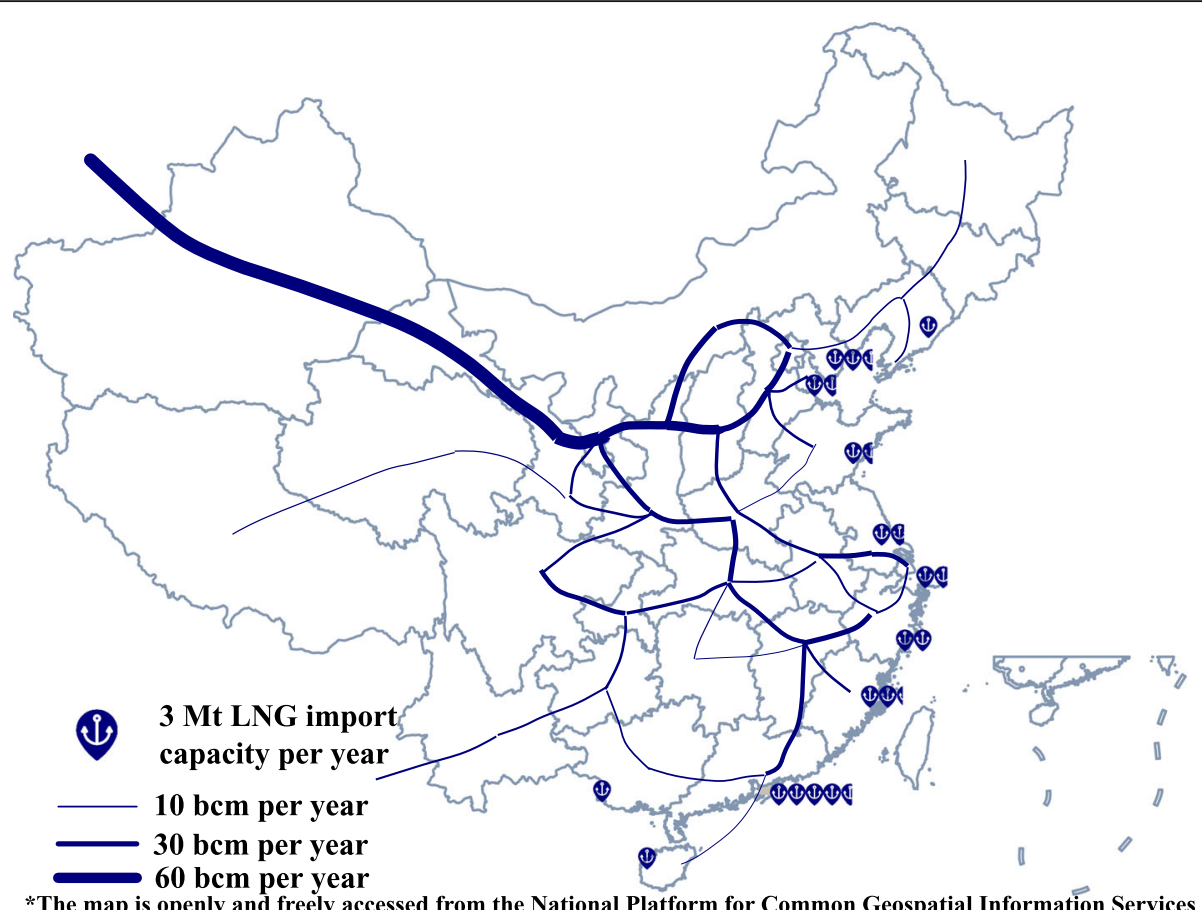

Fig. 3 China's cross-provincial natural gas pipeline network and LNG port in 2017

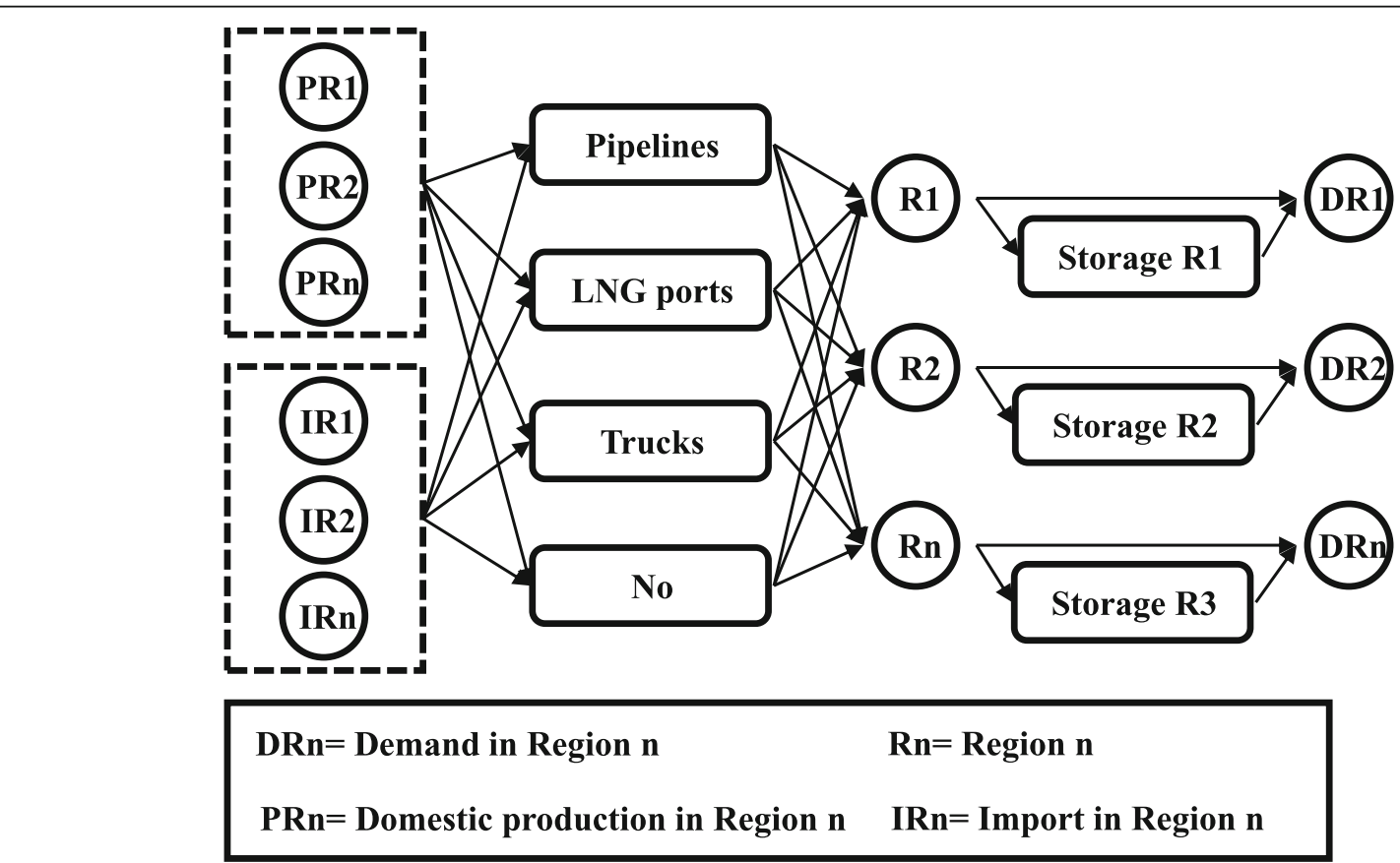

Fig. 4 Framework of a natural gas supply system 
rapid construction of infrastructure, and large disparities over space and time. The optimal distribution strategy and the optimal infrastructure planning by 2050 is obtained by minimizing the overall cost.

The space and time scale of modelling research is improved in this study, which describes natural gas transmission among 30 regions, balance of supply and demand in each month, and infrastructure expansion in a long period.

This paper is organized as follows. In Section two, the methodology is illustrated. In Section three, China's natural gas supply system is introduced as a case study. In Section four, results are analyzed, and policy suggestions are discussed. In Section five, main conclusions are summarized.

\section{Methods}

\section{Generic framework of natural gas supply systems}

A generic framework of natural gas supply systems with multi-regions and multi-periods comprises five parts, namely domestic production, import, transmission, storage and demand part, as shown in Fig. 4.

In the domestic production part, natural gas resources and production capacity are different regionally. Similarly, the import capacity is different regionally depending on the import infrastructure, including pipelines and LNG ports. Natural gas transmission has four options, namely pipelines, LNG ports, trucks and no transmission. The transmission cost is different using these technologies. The storage capacity, depending on storage facilities, serves the purpose of managing monthly fluctuations of natural gas demand and holding safety threshold above a certain level to deal with unexpected and unpredictable risks. In the demand section, yearly natural gas demand and monthly fluctuations are different regionally.

\section{Mathematical model}

The Mix Integer Programming (MIP) method is applied to represent a natural gas supply system. Generic expression of a MIP problem is shown in Eq. 1, where $\boldsymbol{x}$, $\boldsymbol{d}, \boldsymbol{y}, \boldsymbol{\theta}$ represents a vector of continuous operational variables, continuous design variables, binary design variables and input parameters respectively. Function $\boldsymbol{f}, \boldsymbol{h}$, $g$ represents objective function, equality and inequality constraints respectively.

$$
\begin{gathered}
\min \boldsymbol{f}(\boldsymbol{x}, \boldsymbol{d}, \boldsymbol{y}, \boldsymbol{\theta}) \\
\text { s.t. } \boldsymbol{h}(\boldsymbol{x}, \boldsymbol{d}, \boldsymbol{\theta})=\mathbf{0}, \\
g(\boldsymbol{x}, \boldsymbol{d}, \boldsymbol{y}, \boldsymbol{\theta}) \leq \mathbf{0}
\end{gathered}
$$

In this model, monthly natural gas production, import, transmission and storage in each region are operational variables. Expansions of natural gas pipelines, ports and storage facilities year by year are design variables. Resources, geographic location, costs, prices, monthly demand, yearly production capacity and natural gas infrastructure in the base year are input parameters.

Balance between supply and demand in each region, storage balance amongst periods, and infrastructure development year by year mainly make up equality constrains. Inequality constraints generally result from resources, infrastructure limitation and geographic restrictions. The objective function is the overall cost of a natural gas supply system in a long period. Those variables can be obtained by minimizing the objective function.

The detailed is showed below. The following Eq. 222 make up a MIP problem. The MIP problem is solved on the platform of General Algebraic Modeling System (GAMS) [38]. The CPLEX solver is used to solve the problem. The notation is listed in the Abbreviations Part.

\section{Domestic production and import}

Domestic production and net import make up total natural gas supply. The model assumes insufficient domestic natural gas production and sufficient international natural gas supply. Therefore, monthly and overall natural gas production, marked as $\boldsymbol{p r o}_{r, t, \boldsymbol{m}}$ and $\boldsymbol{p r o}_{r}, \boldsymbol{t}$, are constrained by production capacity $\boldsymbol{P} \boldsymbol{R}_{\text {max }, \boldsymbol{r}, \boldsymbol{t}}$ and resources $\boldsymbol{R} \boldsymbol{E}_{\boldsymbol{r}}$ where $\boldsymbol{r}, \boldsymbol{t}, \boldsymbol{m}$ represent region, year and month respectively, as shown in Eqs. 2 and 3. Natural gas import $\boldsymbol{i}_{\boldsymbol{r}, \boldsymbol{t}, \boldsymbol{m}}$ is constrained by import capacity $\boldsymbol{I}_{\max , \boldsymbol{r}, \boldsymbol{t}}$, as shown in Eq. 4. Considering that natural gas production is relatively stable, a parameter $\boldsymbol{A}$ is set to represent the maximum gap between natural gas production and monthly average production, as shown in Eq. 5.

$$
\begin{aligned}
& \sum_{m} \text { pro }_{r, t, m} \leq P R_{\max , r, t} \\
& \sum_{t} \operatorname{pro}_{r, t} \leq R E_{r} \\
& i_{r, t, m} \leq I_{\text {max }, r, t} / 12 \\
& \left(\sum_{m} \text { pro }_{r, t, m} / 12\right) \\
& \times(1-A) \leq \text { pro }_{r, t, m} \leq\left(\sum_{m} \text { pro }_{r, t, m} / 12\right) \\
& \times(\mathbf{1}+\boldsymbol{A})
\end{aligned}
$$

\section{Transmission}

Natural gas transmission greatly relies on the specialized infrastructure. Pipeline networks are main methods to 
transmit natural gas in a long distance. In this model, only transmission amongst regions are considered, whilst transmission within a region is neglected. Due to the fact that the amount of natural gas transmitted via other means, truck for instance, is negligible compared with pipeline transmission, other transmission ways are neglected in this study.

Natural gas can only be transmitted between two adjacent regions, and the transmission quantity $\boldsymbol{t}_{\boldsymbol{r}, \boldsymbol{r}, \boldsymbol{t}, \boldsymbol{m}}$ cannot exceed the upper bound constrained by infrastructure $\boldsymbol{T}_{\boldsymbol{m a x}, \boldsymbol{r}, \boldsymbol{r}, \boldsymbol{t}, \boldsymbol{t}}$ as shown in Eq. 6 . A binary variable $\boldsymbol{y} \boldsymbol{t}_{\boldsymbol{r}, \boldsymbol{r} r}$ is introduced to represent geographic constraints, where $y t_{r, r r}$ equals to zero representing two regions are not adjacent, as shown in Eq. 7.

$$
\begin{gathered}
t_{r, r r, t, m} \leq T_{\max , r, r r, t} / 12 \\
-L_{1} \times y t_{r, r r} \leq t_{r, r r, t, m} \leq L_{1} \times y t_{r, r r} \\
\quad\left(y t_{r, r r}-1\right) \times L_{1} \leq t_{r, r r, t, m}
\end{gathered}
$$

\section{Storage}

Natural gas storage facilities play an important role in meeting peak demand. Natural gas storage is constrained with capacity and period, where storage quantity $\boldsymbol{s}_{\boldsymbol{r}, \boldsymbol{t}, \boldsymbol{m}}$ cannot exceed its maximum capacity $S_{\text {max }, r, t}$, as shown in Eq. 8, and ending stock of this period $s \mathbf{1}_{r, t, m-1}$, equals the beginning of the next period $\boldsymbol{s} \mathbf{0}_{r, t, \boldsymbol{m}}$, as shown in Eq. 9.

$$
\begin{aligned}
& s_{r, t, m} \leq S_{\max , r, t} \\
& s 0_{r, t, m}=s \mathbf{1}_{r, t, m-1}
\end{aligned}
$$

\section{Balance of supply and demand}

This work takes a monthly scale to reflect seasonal fluctuations of natural gas demand. In each region and in each month, total supply equals total demand. Total supply comprises of domestic production, net import, net transmission from other regions and net storage reduction, as shown in Eq. 10.

$$
\begin{aligned}
& D_{r, t, m}=p \boldsymbol{o}_{r, t, m}+i_{r, t, m} \\
& +\sum_{r r}\left(\boldsymbol{t}_{r r, r, t, m}-\boldsymbol{t}_{r, r r, t, m}\right)-\boldsymbol{e}_{r, t, m} \\
& +s \mathbf{0}_{r, t, m}-s \mathbf{1}_{r, t, m}
\end{aligned}
$$

Monthly natural gas demand in all regions are input parameters in this model. Monthly fluctuations of demand are different in end-users, namely heating, power generation and other industry demand.
Regional fluctuations can be obtained according to the proportion of natural gas demand in end-users.

\section{Infrastructure expansion}

Along with the increase of the natural gas demand, more pipelines, LNG ports and storage facilities would be constructed. The increasing infrastructure would promote the supply capacity of natural gas. Expansions of natural gas storage facilities are continuous design variables, shown in Eq. 11, whilst expansions of pipelines and ports are discontinuous variables. The new capacity is an integer multiple of the standard capacity, marked as $N T_{0}$ and $N I_{0}$. Bin-

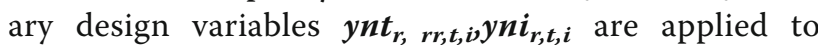
describe it, as shown in Eqs. 12 and 13.

The infrastructure expansion also has geographical constraints. New pipelines can only be constructed between two adjacent regions, and new LNG ports can only be constructed in coastal regions. A binary variable $\boldsymbol{y} \boldsymbol{i}_{\boldsymbol{r}}$ is introduced to represent whether a region is coastal or not, as shown in Eqs. 14 and 15.

$$
\begin{gathered}
S_{\text {max }, r, t}=S_{\text {max }, r, t 0}+\sum_{t=t_{0}}^{t} N S_{r, t} \\
t_{r, r r, t, m} \leq\left(T_{\text {max }, r, r, t 0}+\sum_{t=t_{0}}^{t} \sum_{i=1}^{5} N T_{0} \times\left(y n t_{r, r r, t, i} \times 2^{i-1}\right)\right) / 12 \\
i_{r, t, m} \leq\left(I_{\text {max }, r, t 0}+\sum_{t=t_{0}}^{t} \sum_{i=1}^{5} N T_{0} \times\left(y n i_{r, t, i} \times 2^{i-1}\right)\right) / 12 \\
-L_{2} \times y t_{r, r r} \leq \sum_{i=1}^{5} N T_{0} \times\left(y n t_{r, r r, t, i} \times 2^{i-1}\right) \leq L_{2} \\
\times y t_{r, r r}\left(y t_{r, r r}-1\right) \times L_{2} \leq \sum_{i=1}^{5} N T_{0} \\
\times\left(y n t_{r, r r, t, i} \times 2^{i-1}\right) \\
-L_{3} \times y i_{r} \leq \sum_{i=1}^{5} N I_{0} \times\left(y n i_{r, t, i} \times 2^{i-1}\right) \leq L_{3} \times y i_{r} \\
\left(y i_{r}-1\right) \times L_{3} \leq \sum_{i=1}^{5} N I_{0} \times\left(y n i_{r, t, i} \times 2^{i-1}\right)
\end{gathered}
$$

\section{Objective function}

The optimization objective is the overall supply cost of a natural gas supply system at a transient period. The overall cost is aggregated from annual costs using a discount rate, as shown in Eq. 16. Annual costs comprise 
of domestic production costs, import costs, transmission costs, storage costs, and infrastructure construction costs, as shown in Eq. 17.

Domestic production costs are calculated by multiplying the wellhead price by the natural gas output, as shown in Eq. 18. Import costs consist of import prices, tax and gasification costs, as shown in Eq. 19. Equation 20 shows that transmission costs equal to transmission prices multiplied by transmission quantity. Storage costs are regarded as depreciation, which equals to the value of storage quantity multiplied by the discount rate, as shown in Eq. 21. Equation 22 shows the infrastructure expansion costs.

$$
\begin{aligned}
& c=\sum_{t} c_{t} *(1-D R)^{t-1} \\
& c_{t}=\sum_{r, m}\left(c p_{r, t, m}+c i_{r, t, m}+\sum_{r r} c t_{r, r r, t, m}+c s_{r, t, m}\right) \\
& +\sum_{r} c c_{t} \\
& c \boldsymbol{p}_{r, t, m}=\boldsymbol{P} \boldsymbol{P}_{r, t, m} * \boldsymbol{p r o}_{r, t, m} \\
& c \boldsymbol{i}_{r, t, m}=\boldsymbol{i}_{r, t, m} *\left(P I_{r, t, m}+P G_{r, t, m}\right) *(1+\boldsymbol{T a x}) \\
& c t_{r, r r, t, m}=t_{r, r r, t, m} * P T_{r, r r, t, m} \\
& c s_{r, r r, t, m}=s 1_{r, t, m} * P_{r, t, m} * D R / 12 \\
& c c_{t}=N S_{r, t} \times P N S_{t}+N I_{0} \times\left(y n i_{r, t, i} \times 2^{i-1}\right) \\
& \times P N I_{r, t}+N T_{0} \times\left(y n t_{r, r r, t, i} \times 2^{i-1}\right) \\
& \times P N T_{r, r r, t}
\end{aligned}
$$

In this work, the objective function only considers the costs in supply chains. It is expected to reflect the result of market competition considering policy situation, where China's natural gas market is reforming in a more competitive direction, with more suppliers and centralized management of pipelines. The lowest cost in supply chains is equivalent to the market equilibrium state. Otherwise, if there is a strategy that makes the cost lower, then there must be players in the market who adopt this strategy to gain benefits by reducing the cost. Social costs and the cost associated with shortage of supply exist indeed, but they are not reflected in current market mechanisms, which means the cost would not affect the NG transportation. Therefore, only the costs in supply chains are considered to reflect the result of market competition.

\section{Uncertainty analysis}

This model is developed to find out the optimal infrastructure expansion plan and natural gas distribution strategy by minimizing the overall cost. Because of that, main uncertainties of the model derive from the gap between demand and supply, costs in the supply chain, and the discount rate. In this study, this methodology is applied in China's natural gas supply system, where domestic natural gas is insufficient and has lower prices than import natural gas. Therefore, demand forecast, transmission cost, import cost and the discount rate are main parameters that would affect the result greatly.

The uncertainty analysis of the model is performed by increasing or decreasing these main parameters by $5 \%$. Some indicators are selected to show the impact on the results, which are the overall cost, cumulative investment on pipelines, cumulative new LNG import capacity, and cumulative storage capacity. These four indicators reflect the impact on the overall cost, pipeline expansion plan, LNG port expansion plan and storage capacity expansion plan. The result is listed in Table 1.

Results show that demand forecast has more impacts than the other parameters. Higher demand forecast would lead to further infrastructure expansion and more natural gas transmission.

\section{Case study}

The methodology developed above is applied to model and optimize the natural gas supply system in China.

\section{Regions and periods set}

There are 30 regions in the model representing 30 out of the total 34 provinces of China, as shown in Fig. 5, where Hong Kong, Macao, Taiwan and Tibet are not included due to data availability issues. The time resolution is at a monthly scale. The planning period is from 2015 to 2050 .

\section{China's natural gas supply system}

The natural gas supply system in this model consists of import facilities, cross-provincial transmission pipelines and storage facilities, whilst transmission pipelines inside a province are neglected.

\section{Import facilities}

China's natural gas import has been increasing fast in recent years, and the external dependent degree has exceed $40 \%$. Natural gas import facilities in China comprise of pipelines and LNG ports.

Import pipeline facilities locate in Northwest and Southwest China, importing natural gas from Central Asia and Myanmar, respectively. Import facilities from Central Asia consist of three pipelines with a total import capability of $55 \mathrm{bcm}$ as of the end of 2017, importing natural gas from Turkmenistan, Uzbekistan, and Kazakhstan. Another 
Table 1 results of the uncertainty analysis

\begin{tabular}{|c|c|c|c|c|c|c|c|c|}
\hline \multirow[t]{2}{*}{ Change of indicators $/ \%$} & \multicolumn{2}{|c|}{ Demand forecast } & \multicolumn{2}{|c|}{ Transmission cost } & \multicolumn{2}{|c|}{ Import cost } & \multicolumn{2}{|c|}{ Discount rate } \\
\hline & +5 & -5 & +5 & -5 & +5 & -5 & $\overline{+5}$ & -5 \\
\hline The overall cost & 6.0 & -5.8 & 0.6 & -0.6 & 2.7 & -2.7 & -3.9 & 4.0 \\
\hline Cumulative investment on pipelines & -2.4 & 4.8 & 10.1 & 4.7 & 4.3 & 4.4 & -3.1 & 3.4 \\
\hline Cumulative new LNG import capacity & 11.3 & -13.9 & 2.5 & -1.3 & 2.5 & 1.3 & -1.3 & 0 \\
\hline Cumulative storage capacity & 11.9 & -9.6 & 0.4 & -8.1 & -3.1 & -3.1 & -5.6 & 3.1 \\
\hline
\end{tabular}

pipeline importing natural gas from Russia is under construction and is expected to be in operation in 2020. The fourth pipeline from Central Asia is listed in 13th-five-year plan and expected to be completed before 2020. Details are shown in Additional file 1.

LNG ports locate in all coastal provinces in China, and the annual import capability has reached $75 \mathrm{bcm}$ by the end of 2017. Details are shown in Additional file 2.

\section{Cross-provincial natural gas pipelines in China}

The spatial mismatch of natural gas supply and demand in China requires complex pipeline networks, especially high-pressure cross-provincial pipelines. Total mileage of cross-provincial natural gas pipelines in China has reached $64,000 \mathrm{~km}$ in 2015 , and it is expected to exceed $104,000 \mathrm{~km}$ in 2020 [29]. Details of pipelines are shown in Additional file 3.

\section{Natural gas storage facilities in China}

The storage capability in operation only accounts for 3 $\%$ of total natural gas consumption in China, which means the peaking capability is insufficient and the temporal fluctuations of demand have a significant impact on operation of the pipeline system. Underground gas

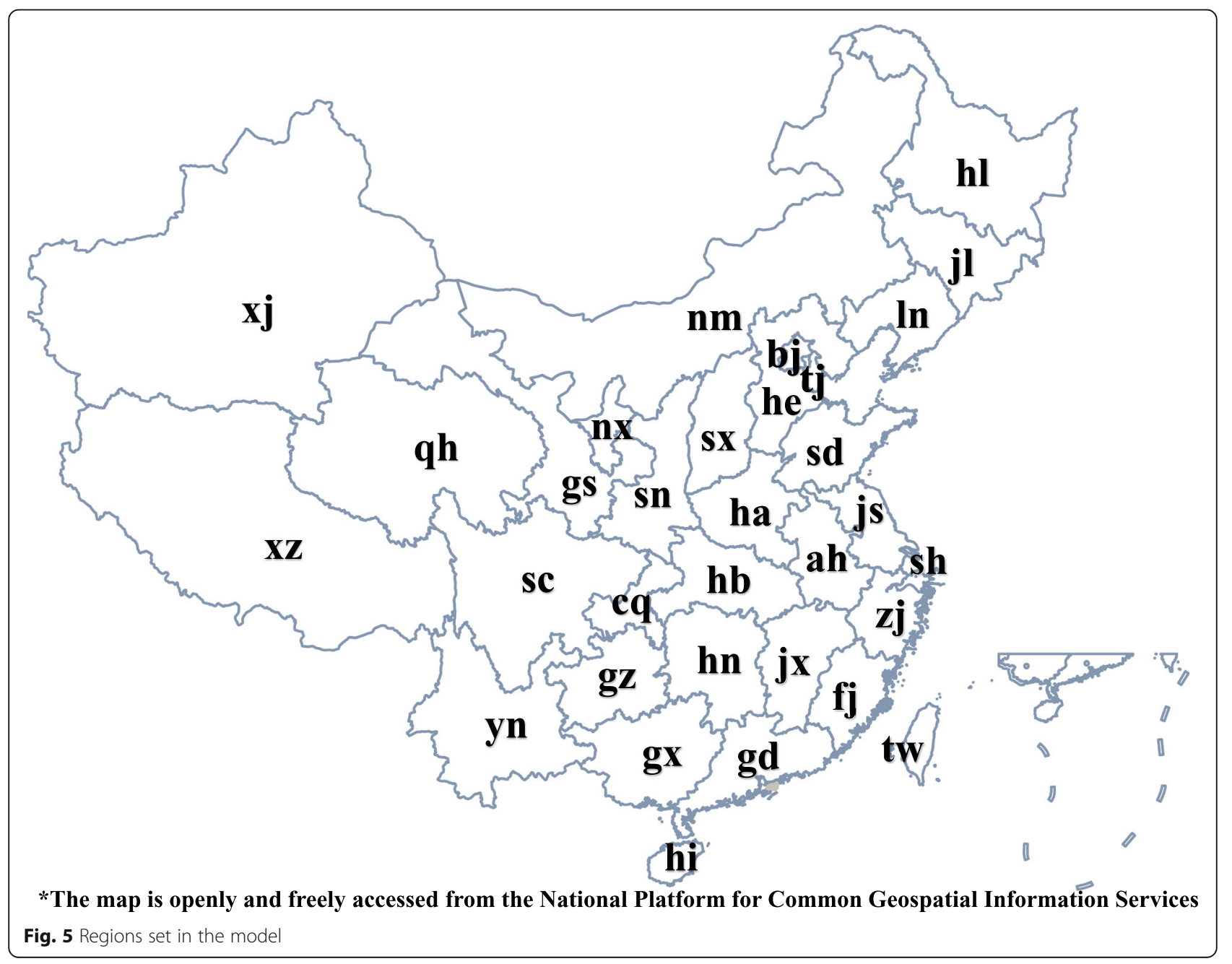


storage is the main storage facilities, located in eight provinces of China. Total storage capability in operation is $7 \mathrm{bcm}$ by the year of 2017. Details are shown in Additional file 4.

\section{Current policies on natural gas transmission and pricing}

The long-distance natural gas transmission in China is now mainly operated by three companies mentioned before. The transmission fee of each pipeline is fixed, which is audited, regulated and disclosed by the central government.

The natural gas pricing mechanism is half marketoriented depending on the natural gas resource. The pricing of LNG is fully market-oriented, and the pricing of natural gas transmitted by pipelines is mainly governmentoriented. A series of urban gate station prices transmitted by pipelines in each provinces are set by central government, and the prices could float up a certain percent during high demand seasons.

\section{Data}

In this study, future natural gas production capacity is estimated according to the China's 13th-five-year energy plan. Future demand set mainly comes from the China's 13th-five-year energy plan with modifications according to other researches mentioned before.

The import, transmission, storage capacity and transmission prices are gathered from three national oil and natural gas companies, China National Petroleum Corp (CNPC) [36], China Petroleum \& Chemical Corporation (Sinopec) [35] and China National Offshore Oil Corporation (CNOOC) [37]. The historical production and demand in each province are obtained from China Energy Statistical Yearbook [27]. The well prices and sale prices of natural gas are gathered from National Development and Reform Commission, as shown in Additional file 5.

\section{Scenarios settings}

Three groups of scenarios are set for comparison purposes, namely historical scenarios, short-term scenarios and long-term scenarios.

\section{Historical scenarios}

Historical scenarios include the simulation scenario and the optimization scenario with the purpose of indicating the difference between actual and the optimal strategies from 2015 to 2017. In the simulation scenario, actual historical data are collected and put into the model, including provincial and monthly production, import and consumption data. Simulation results can show the operation status of the supply system. In the optimization scenario, the total supply cost is minimized to obtain the optimal natural gas distribution strategy. The optimal strategy would indicate the optimal selection of locations and quantities for natural gas import and also how to distribute natural gas to all regions.

\section{Short-term scenarios}

Short-term scenarios use the China's infrastructure formulation as input to optimize the operation of the natural gas supply system under different demand forecasts up to 2020 . Short-term scenarios are designed to study whether existing infrastructure plans match natural gas demand expectations.

The natural gas demand forecast in short-term scenarios are generated based on projections of China and each province. It should be pointed out that there is a gap between the China's projection to the overall natural gas demand in 2020 and the summation of projections

Table 2 Natural gas demand in each province (bcm)

\begin{tabular}{|c|c|c|c|c|c|}
\hline Scenario & All & The 13th-five-year plan & S385 & L3 & L3 \\
\hline Year & 2015 & 2020 & 2020 & 2035 & 2050 \\
\hline bj & 14.7 & 19.0 & 19.0 & 209.4 & 207.7 \\
\hline tj & 6.4 & 11.6 & 11.6 & 224.4 & 245.2 \\
\hline he & 7.3 & 27.3 & 27.3 & 559.2 & 646.7 \\
\hline sx & 6.5 & 16.0 & 16.0 & 335.6 & 369.2 \\
\hline $\mathrm{nm}$ & 3.9 & 8.0 & 8.0 & 194.6 & 252.2 \\
\hline $\ln$ & 5.5 & 16.8 & 13.0 & 250.9 & 283.6 \\
\hline jl & 2.1 & 6.0 & 4.7 & 98.5 & 150.6 \\
\hline hl & 3.6 & 9.3 & 6.9 & 154.6 & 233.8 \\
\hline sh & 7.7 & 12.5 & 12.5 & 245.2 & 215.3 \\
\hline js & 16.5 & 35.0 & 35.0 & 609.3 & 726.0 \\
\hline zj & 8.0 & 18.3 & 18.3 & 383.1 & 422.1 \\
\hline ah & 3.5 & 7.0 & 7.0 & 203.1 & 209.7 \\
\hline $\mathrm{fj}$ & 4.5 & 9.2 & 9.2 & 199.6 & 167.6 \\
\hline jx & 1.8 & 6.5 & 7.3 & 167.0 & 135.2 \\
\hline $\mathrm{sd}$ & 8.2 & 25.0 & 25.0 & 514.0 & 551.9 \\
\hline ha & 7.9 & 16.7 & 16.7 & 352.1 & 402.0 \\
\hline hb & 4.0 & 11.3 & 6.0 & 179.5 & 171.0 \\
\hline hn & 2.7 & 8.5 & 3.8 & 157.1 & 196.9 \\
\hline $\mathrm{gd}$ & 14.5 & 33.8 & 33.8 & 438.6 & 510.3 \\
\hline$g x$ & 0.8 & 7.3 & 7.3 & 115.0 & 89.3 \\
\hline hi & 4.6 & 6.1 & 6.1 & 62.1 & 51.1 \\
\hline $\mathrm{cq}$ & 8.8 & 12.4 & 12.4 & 393.6 & 421.9 \\
\hline SC & 17.1 & 28.0 & 28.0 & 620.6 & 642.7 \\
\hline$g z$ & 1.3 & 4.9 & 1.1 & 94.6 & 155.3 \\
\hline yn & 0.6 & 3.6 & 0.9 & 50.8 & 119.6 \\
\hline sn & 8.3 & 11.6 & 11.6 & 350.8 & 474.9 \\
\hline gs & 2.6 & 3.7 & 3.7 & 169.6 & 179.2 \\
\hline qh & 4.4 & 7.1 & 7.1 & 86.5 & 65.6 \\
\hline$n x$ & 2.1 & 3.0 & 3.0 & 83.2 & 93.2 \\
\hline$x j$ & 14.6 & 22.4 & 22.4 & 278.9 & 305.8 \\
\hline
\end{tabular}


Table 3 National natural gas forecasts in short-term scenarios (bcm)

\begin{tabular}{lllll}
\hline Note & S385 (Basic) & S360 & S340 & S330 \\
\hline Demand in 2020 & 385 & 360 & 340 & 330 \\
\hline
\end{tabular}

of all provinces, $370 \mathrm{bcm}$ and $408 \mathrm{bcm}$, respectively. In our study, we take an average projection of $385 \mathrm{bcm}$ as the basic scenario modified from province projections, as shown in Table 2.

The basic short-term scenario with a $385 \mathrm{bcm}$ demand forecast is marked as S385. Three comparison scenarios with different demand forecasts are set to indicate the impact on operation strategy, as shown in Table 3. Then the optimal operation strategy of China's natural gas system can be obtained by minimizing the total supply cost.

\section{Long-term scenarios}

Long-term scenarios are set to obtain the optimal planning of infrastructure expansions as well as natural gas distribution strategies from 2015 to 2050 .
Table 4 National natural gas forecasts in long-term scenarios (bcm)

\begin{tabular}{lllll}
\hline Natural gas demand & L1 & L2 & L3 (Basic) & L4 \\
\hline 2020 & 313 & 327 & 342 & 354 \\
2035 & 603 & 691 & 778 & 864 \\
2050 & 667 & 765 & 870 & 965 \\
\hline
\end{tabular}

According to the uncertainty analysis, demand forecast has great effects on the result. In this case study, natural gas transmission cost is regulated by the government, and it is considered constant for a long time. Therefore, scenarios are set, marked as L1-4, based on different demand forecast in long-term scenarios, as shown in Table 4.

Natural gas demand forecast in basic scenario L3 is set according to China's projection that natural gas demand accounts for $15 \%$ in 2030 . The demand in 2030 is estimated to be around $750 \mathrm{bcm}$. The provincial demand decomposition is shown in Table 2.

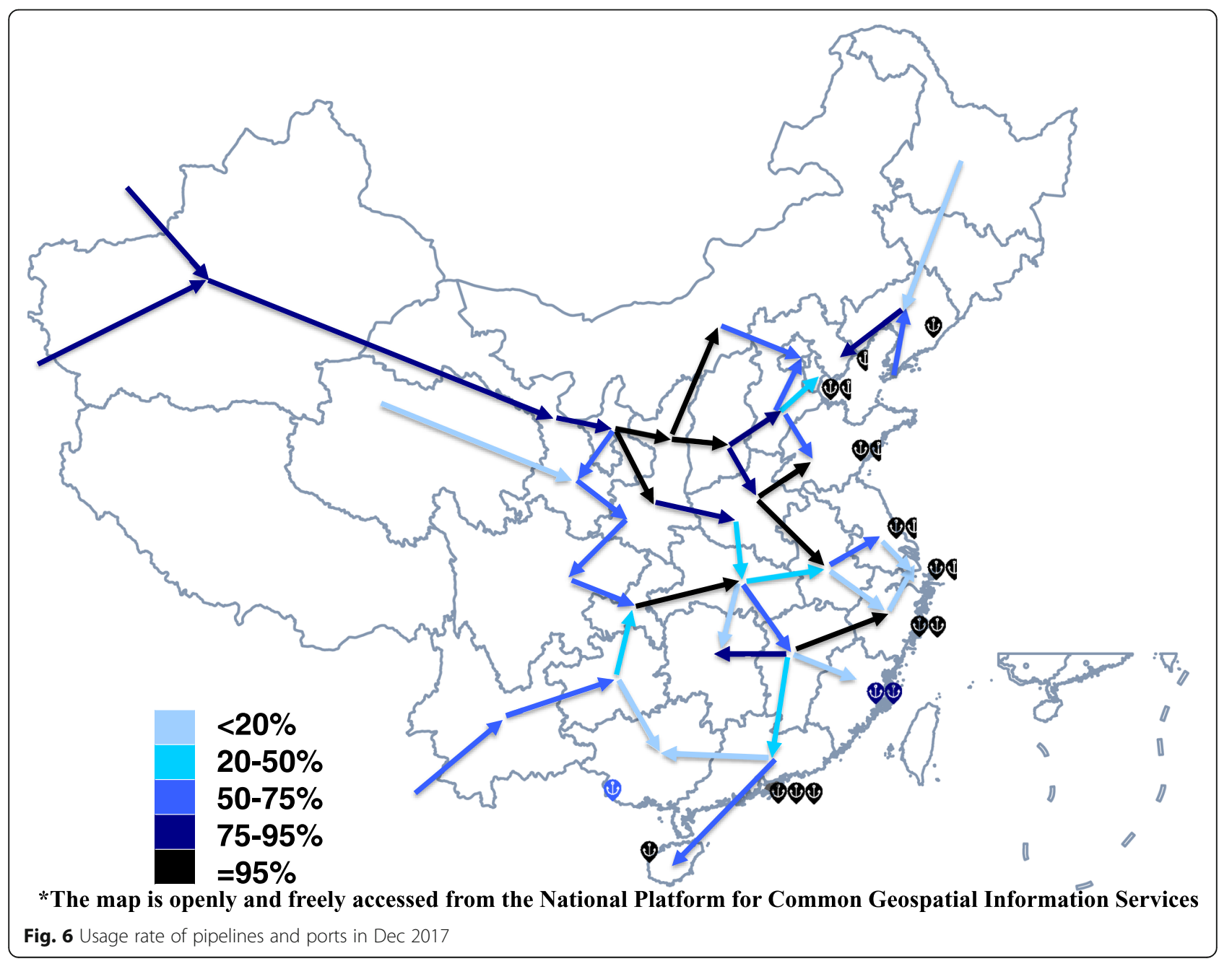




\section{Results}

Simulation of the natural gas shortage in 2017

In the historical simulation scenario, results present operation status of China's natural gas supply system from 2015 to 2017. Figure 6 shows the usage rate of natural gas infrastructure in Dec 2017, when a natural gas shortage occurred in China. It indicates that the infrastructure utilization reaches its upper bound in North China. All LNG ports are running at the highest load or even overloaded.

\section{Optimal natural gas distribution strategy}

In the historical optimization scenario, the optimal strategy of natural gas distribution can be summarized by comparing results with the historical simulation scenario.

The optimal strategy can be summarized as the shortest distance transmission. In warm days, from April to October, natural gas produced in West China and imported from Central Asia need to meet the demand in North and East China, and LNG need to be imported only in South China. In cold days, from November to next March, LNG need to be imported not only in South China but in North China due to great heating demand.

The actual distribution strategy and the optimal strategy are different to some extent. Results from the simulation scenario indicate that, in warm days, LNG is imported in North China, and natural gas from Central Asia is transmitted to South China. That would increase the supply cost in North China and decrease the supply cost in South China, whilst the total supply cost is higher.

The total supply cost can be lower by taking the optimal strategy, whilst the potential cost reduction space is limited, because the infrastructure utilization is close to the upper bound. Only 10 billion yuan of the import cost and 7 billion yuan of the transmission cost can be saved by taking the optimal strategy in 2017, whilst the annual supply cost reaches 391 billion yuan. The production, transmission and import cost account for 38, 15 and $47 \%$ respectively, whilst the storage cost accounts for less than $1 \%$. It indicates that if international natural gas prices rise by $1 \%$, the total supply cost in China would rise by $0.47 \%$.

\section{Mismatch between demand projections and infrastructure planning}

In short-term scenarios, if the optimal solution exists, it will indicate the infrastructure planning could secure the

Table 5 Results in short-term scenarios

\begin{tabular}{lll}
\hline Scenarios & Optimal solution & Natural gas shortage \\
\hline S385 & No & $8.2 \mathrm{bcm}$ in Eastern China \\
S360 & No & $4.2 \mathrm{bcm}$ in Eastern China \\
S340 & No & $1.2 \mathrm{bcm}$ in Jiangsu province \\
S330 & Yes & No \\
\hline
\end{tabular}

natural gas supply to meet the demand. If the optimal solution does not exist, it will indicate that the demand could not be met under the current planning. Results are summarized in Table 5.

In S385, S360 and S340 scenarios, results show that the natural gas supply cannot meet the demand under the infrastructure planning in the China's 13th-five-year plan. In the S330 scenario, the balance between supply and demand can be achieved, and the optimal distribution strategy can be obtained. It indicates that the natural gas demand projection is inconsistent with current infrastructure planning.

The mismatch between supply and demand reflects in a regional and monthly scale but not a national and yearly scale. The supply capacity is insufficient only in winter and in eastern regions. For example, results show that $4.2 \mathrm{bcm}$ natural gas demand in East China is uncovered in the S360 scenario. In the meantime, the supply capacity in Southwest China and South China is sufficient throughout the whole year. It indicates that demand projections set by each province are not consistent with the national infrastructure planning.

\section{Optimal planning of the natural gas infrastructure expansion}

In long-term scenarios, the model could obtain the optimal planning of natural gas infrastructure expansions under different demand forecasts in 2050. The optimal planning reflects the construction timetable, including when, where, how much and which kind of infrastructure need to be constructed.

In the L3 scenario, which is the basic scenario, Figs. 7, 8 and 9 show pipelines and import facilities in 2020, 2035 and 2050 respectively. Results indicate that large quantity of pipelines need to be constructed in North China, connecting resources and demand areas, whilst new pipelines in South China need to be constructed much less.

A large number of LNG ports need to be built in most coastal provinces, making LNG a main source to increase natural gas supply before 2050. Figure 10 shows the optimal planning of import capacity expansions in different regions from 2015 to 2050. Results indicate that new LNG ports would be mainly concentrated in eastern and southern coastal provinces before 2035, and new LNG ports would be concentrated in northern coastal regions after 2035. According to the optimal strategy of shortest distance transmission, natural gas demand in East and South China needs to be supplied by more imported LNG, whilst demand in North China can be met by more pipelines.

Continuous expansions of storage capacity are needed to deal with seasonal fluctuations of natural gas demand 


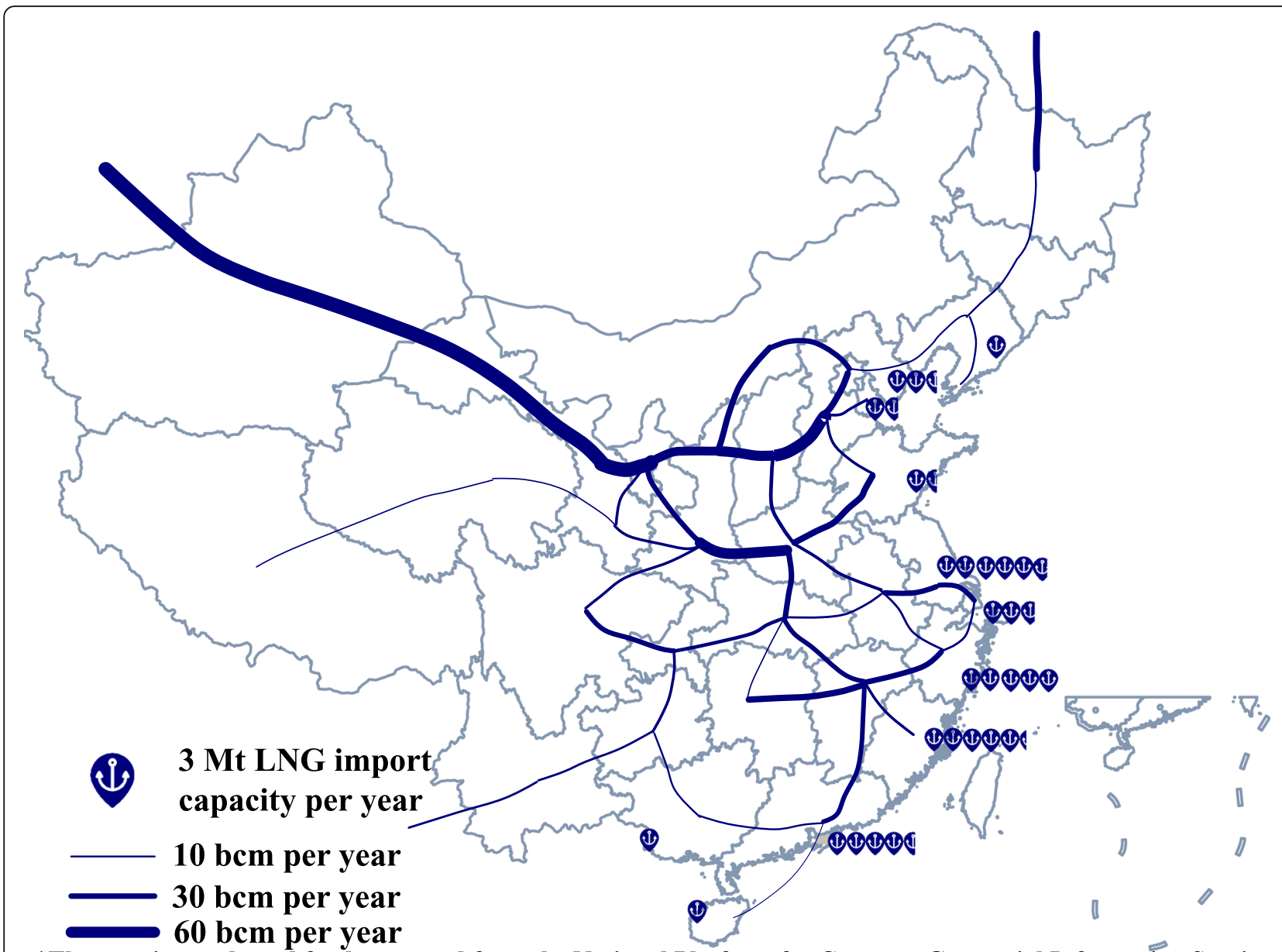

*The map is openly and freely accessed from the National Platform for Common Geospatial Information Services

Fig. 7 Capacity of pipelines and LNG ports in 2020

and other unknown risks. Figure 11 shows the optimal storage planning of capacity expansions in different regions from 2015 to 2050. Results indicate that new storage facilities are mainly concentrated in North China to deal with heating demand in cold days. Meanwhile, policies on establishing reserves to deal with risks also have great effects on the planning. Rapid increase in storage capacity in 2020 results from those policies.

As for the impact of different demand forecasts on infrastructure planning, results show that higher demand forecasts could result in more infrastructure costs. Figure 12 shows the composition of infrastructure costs under different demand forecasts. It indicates that the impact of demand forecasts on the pipeline expansion is less than the impact on LNG ports and storage facilities. Current natural gas pipelines transport natural gas from inland areas to coastal areas. As natural gas demand increases, coastal areas would mainly meet demand by imported LNG. Therefore, the increase in natural gas demand would not greatly affect the construction of the pipeline network.

\section{Discussion and policy suggestions}

Policy suggestions are further discussed based on above analysis. First, taking market-oriented pricing mechanisms as much as possible, which reflect the relationship between supply and demand. Full market-oriented pricing can achieve the optimal distribution strategy and minimize the total supply cost. Current pricing mechanisms are not fully market-oriented, and natural gas can be divided into pipeline natural gas and LNG by source. LNG pricing fully depends on market, whilst prices of pipeline natural gas are still guided by the regulatory authority.

The difference between the actual distribution strategy and the optimal strategy mainly derives from incomplete market-oriented pricing in contracts. The optimal strategy indicates to deliver 


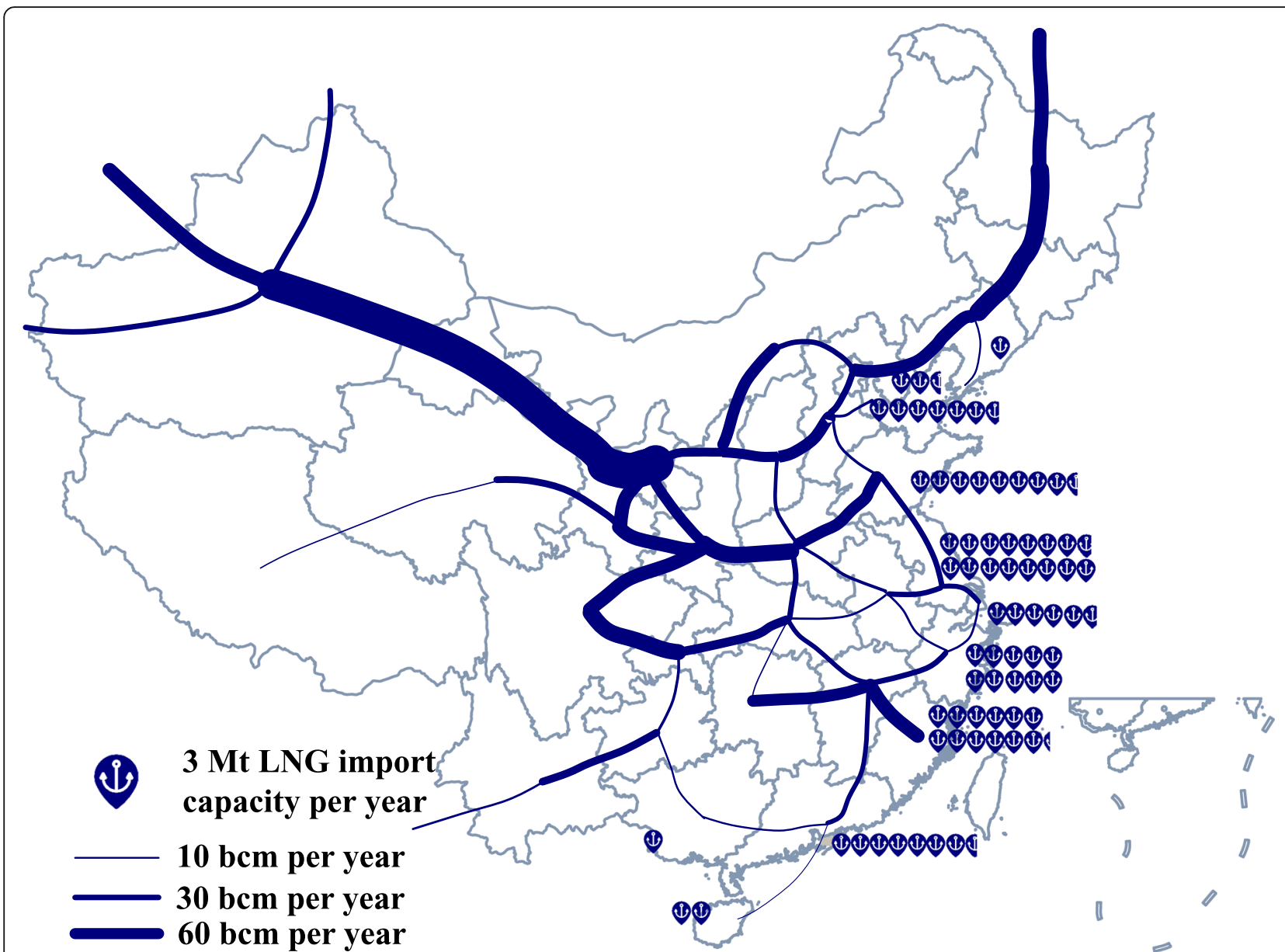

*The map is openly and freely accessed from the National Platform for Common Geospatial Information Services

Fig. 8 Capacity of pipelines and LNG ports in 2035

natural gas resources flexibly, rather than binding natural gas resources to fixed users all year along without considering the monthly variation. In the simulation scenario, the natural gas imported from Central Asia is transmitted to South China all the year. If market-oriented pricing is applied, which means that the highest bidder wins, the natural gas imported from Central Asia could be auctioned by users in the north, and users in south would import more LNG.

Secondly, natural gas pipelines should be centrally managed as a public resource and provides fair access to market participants. Natural gas pipelines have natural monopoly properties, and main pipelines are operated by a limited number of giant companies. This monopoly could increase the price in regions with a single natural gas supplier, because other suppliers cannot access these pipelines. It could lead to a spacial mismatch of natural gas resources and consumption compared with the optimal supply strategy. To achieve market-oriented pricing, more suppliers are required in the market to promote the competition. If all infrastructure is managed as a public resource, more suppliers would have access to the natural gas market.

Thirdly, improving coordination amongst provinces when formulating projections. Main infrastructure planning is in the national projection, which makes up the supply capacity. Province projections are formulated respectively and independently to some extent. Aggregated province projections could exceed or fall below the national projection under insufficient coordination. As shown in results, aggregated province projections exceed the national projection by $14 \%$, which could result in a natural gas shortage by 2020. In order to avoid losses caused by deviations from the national projection, the formulation process of province projections requires uniform coordination.

Forth, infrastructure construction needs to be accelerated, especially LNG ports and storage facilities. LNG imported overseas is expected to account for a large proportion of natural gas supply in the future according to 


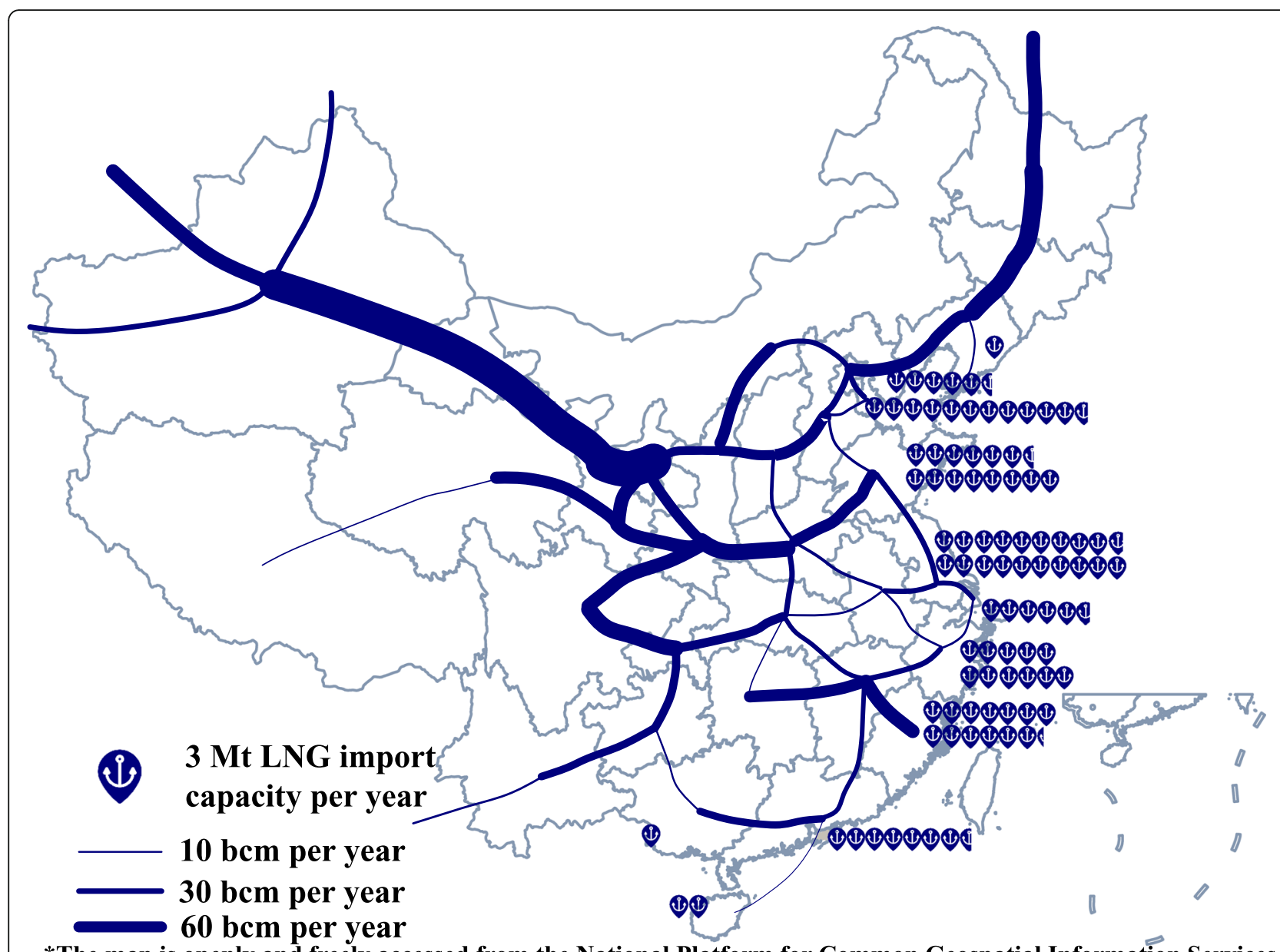

*The map is openly and freely accessed from the National Platform for Common Geospatial Information Services Fig. 9 Capacity of pipelines and LNG ports in 2050

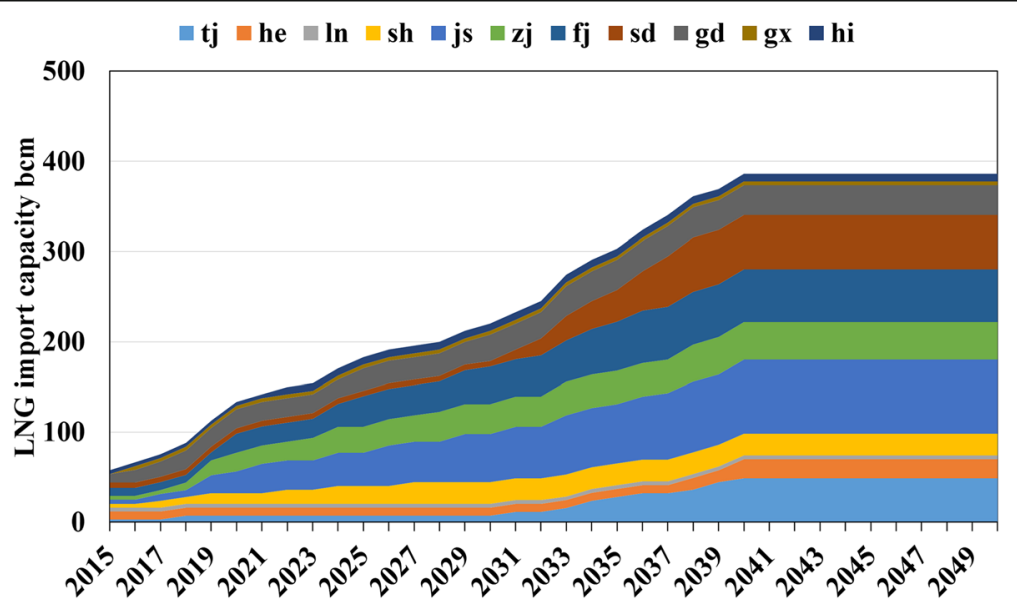

Fig. 10 LNG ports capacity from 2015 to 2050 


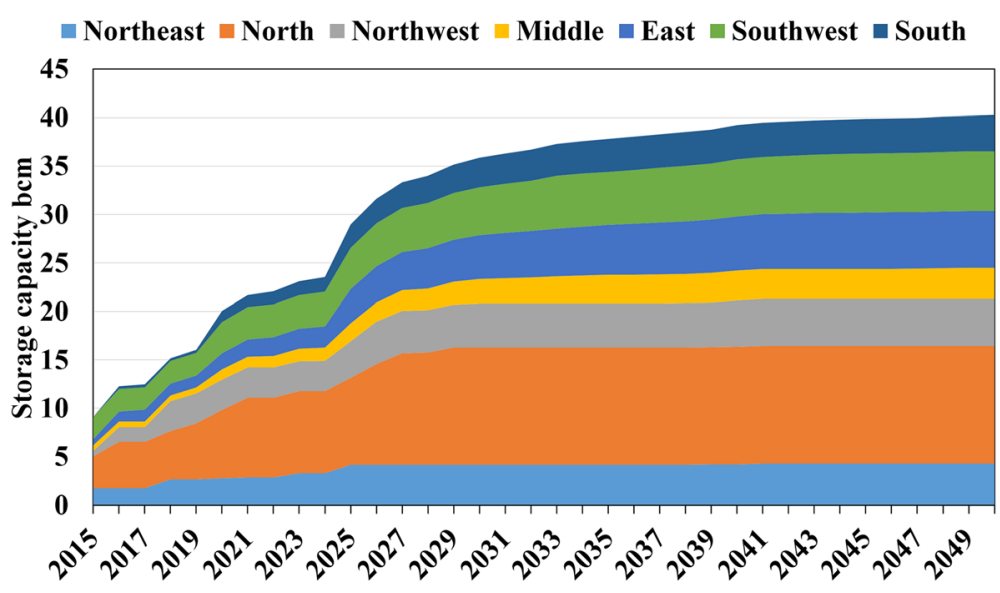

Fig. 11 Storage capacity in different regions from 2015 to 2050

the result. Accelerating the construction of LNG ports in East China would alleviate the overall tight supply situation and reduce the risk of shortage in East China several years later. Accelerating the construction of storage facilities in North China would greatly alleviate the shortage of natural gas in winter in the short term.

Fifth, scientifically predicting natural gas demand enables better infrastructure planning. Premature or later construction of infrastructure would lead to waste and shortage respectively, which would both result in a higher overall cost.

\section{Conclusions}

In this paper, we propose a methodology to develop a monthly-scale multi-period and multi-regional optimization model for natural gas supply system planning at a transient stage. The methodology is applied to analyze China's natural gas supply system. An optimal development strategy of natural gas distribution and infrastructure expansion is obtained by minimizing the total supply cost. Results indicate that natural gas demand forecast has great impacts on the planning. It is also pointed out that a risk of a mismatch between natural gas demand and supply infrastructure development could happen in spacial and temporal dimensions if problems at the planning stage are not properly addressed.

Policy suggestions are provided. Taking marketoriented pricing mechanisms as much as possible, which can achieve the optimal distribution strategy and minimize the total supply cost. Natural gas pipelines needs to be centrally managed as a public good and provide fair access to market participants. Coordination amongst provinces when formulating projections needs to be strengthened. Infrastructure construction needs to be accelerated, especially LNG ports in East China and storage facilities in North China. Predicting future natural gas demand scientifically enables better infrastructure planning.

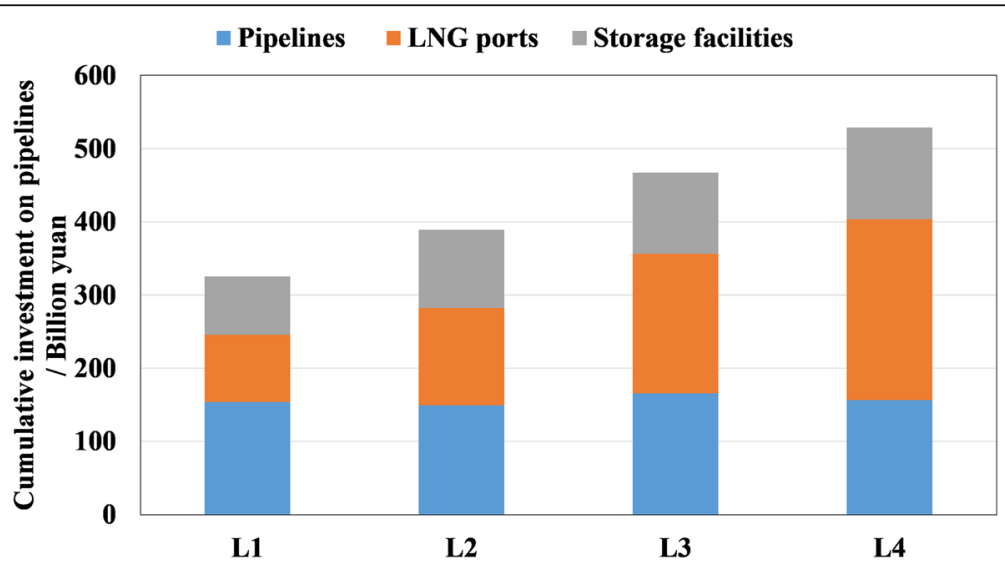

Fig. 12 Infrastructure costs under different demand forecast 


\section{Additional files}

Additional file 1: Import pipeline facilities in China. Location, capacity and status of import pipelines. (DOCX $13 \mathrm{~kb})$

Additional file 2: LNG terminals in China (2017). Location, capacity and status of LNG terminals. (DOCX $14 \mathrm{~kb}$ )

Additional file 3: Cross-provincial natural gas pipelines in China (2017). Location and capacity of pipelines. (DOCX $15 \mathrm{~kb}$ )

Additional file 4: Underground gas storage in China (2017). Location and capacity of storage facilities. (DOCX $13 \mathrm{~kb}$ )

Additional file 5: Regulated natural gas price in each province (yuan/ $\mathrm{cm}$ ). Sale prices and well prices in each province. (DOCX $13 \mathrm{~kb}$ )

\section{Abbreviations \\ Subscripts \\ $r$ : Regions in China; $t$ : Year, from 2015 to 2020; m: Month, from 1 to 12}

\section{Parameters}

$D$ : Quantity of natural gas demand; $D R$ : Discount rate; $I_{\text {max }}$ : Upper bound of natural gas import; $P P$ : Domestic production price; $T_{\text {max }}$ : Upper bound of natural gas transmission; $P I$ : Import price; $S_{\text {max }}$ : Upper bound of natural gas storage; $P T$ : Transmission price; $P_{r}$ : Downstream natural gas price in region $r_{\text {; }}$ TAX: Tax of importing natural gas; $P R_{\text {max }}$ : Upper bound of natural gas production; $P G$ : Gasify price; $R E$ : Resources; $L_{i}$ : A relatively large positive integer

\section{Variables}

pro: Quantity of natural gas production; c: Overall supply cost; s0: Quantity of natural gas store at the beginning of a month; $c p$ : Production cost: s1: Quantity of natural gas storage at the end of a month; ci: Import cost; $t_{r, r r}$ : Quantity of natural gas transmission from $r$ to $\mathrm{rr}$; $c t$ : Transmission cost; $i_{r}$ : Import in region $r$; $c s$ : Store cost; $e_{r}$ : Export from $r_{;}$cc: Infrastructure construction cost; $N T_{0}$ : Standard capacity of pipelines; $P N S_{r}$ : Storage facilities construction cost; $\mathrm{NI}_{0}$ : Standard capacity of ports; $P N T_{r, r r}$ : Pipelines construction cost; $N S_{r, t}$ : New storage capacity; $P N I_{r}$ : LNG ports construction cost

\section{Acknowledgements}

The authors gratefully acknowledge the support by The National Key Research and Development of China (2018YFB0604301), National Natural Science Foundation of China (71690245) and the Phase III Collaboration between BP and Tsinghua University.

\section{Authors' contributions}

TL developed the mathematical model and conducted the case studies. PL developed the overall modelling and optimization framework. ZL provided insights of natural gas infrastructure expansion. All authors read and approved the final manuscript.

\section{Funding}

The research is funded by the National Key Research and Development of China (2018YFB0604301), National Natural Science Foundation of China (71690245), and the Phase III Collaboration between BP and Tsinghua University.

\section{Availability of data and materials}

The dataset supporting the conclusions of this article is included within the article.

\section{Competing interests}

The authors declare that they have no competing interests.

Received: 20 December 2018 Accepted: 22 May 2019

Published online: 25 June 2019

\section{References}

1. BP. Statistical Review of World Energy. 2018.
2. Moller $\mathrm{B}$, Lund $\mathrm{H}$. Conversion of individual natural gas to district heating: geographical studies of supply costs and consequences for the Danish energy system. Appl Energy. 2010;87(6):1846-57.

3. Jalil-Vega F, Hawkes AD. Spatially resolved model for studying decarbonisation pathways for heat supply and infrastructure trade-offs. Appl Energy. 2018;210:1051-72.

4. Shan XF, Wang P, Lu WZ. The reliability and availability evaluation of repairable district heating networks under changeable external conditions. Appl Energy. 2017;203:686-95.

5. Unternaehrer J, Moret S, Joostb S, Marechal F. Spatial clustering for district heating integration in urban energy systems: application to geothermal energy. Appl Energy. 2017;190:749-63.

6. Pan L, Liu P, Li Z. A system dynamic analysis of China's oil supply chain: over-capacity and energy security issues. Appl Energy. 2017;188:508-20.

7. Alhamwi A, Medjroubi W, Vogt T, Agert C. GIS-based urban energy systems models and tools: introducing a model for the optimisation of flexibilisation technologies in urban areas. Appl Energy. 2017;191:1-9.

8. Han J-H, Lee I-B. Development of a scalable infrastructure model for planning electricity generation and $\mathrm{CO} 2$ mitigation strategies under mandated reduction of GHG emission. Appl Energy. 2011;88(12):5056-68.

9. Guo Z, Ma LW, Liu P, Jones I, Li Z. A multi-regional modelling and optimization approach to China's power generation and transmission planning. Energy. 2016;116:1348-59.

10. Guo Z, Cheng R, Xu ZF, Liu P, Wang Z, Li Z, et al. A multi-region load dispatch model for the long-term optimum planning of China's electricity sector. Appl Energy. 2017;185:556-72.

11. Ghatikar G, Mashayekh S, Stadler M, Yin R, Liu Z. Distributed energy systems integration and demand optimization for autonomous operations and electric grid transactions. Appl Energy. 2016;167:432-48.

12. Shu K, Schneider UA, Scheffran J. Optimizing the bioenergy industry infrastructure: transportation networks and bioenergy plant locations. Appl Energy. 2017;192:247-61.

13. Hwangbo S, Lee I-B, Han J. Mathematical model to optimize design of integrated utility supply network and future global hydrogen supply network under demand uncertainty. Appl Energy. 2017;195:257-67.

14. Rios-Mercado RZ, Borraz-Sanchez C. Optimization problems in natural gas transportation systems: a state-of-the-art review. Appl Energy. 2015;147:536-55.

15. Brkic D. An improvement of hardy cross method applied on looped spatial natural gas distribution networks. Appl Energy. 2009;86(7-8):1290-300.

16. Manojlovic V, Arsenovic M, Pajovic V. Optimized Design of a gas-Distribution Pipeline Network. Appl Energy. 1994;48(3):217-24.

17. Uester H, Dilaveroglu S. Optimization for design and operation of natural gas transmission networks. Appl Energy. 2014;133:56-69.

18. Dieckhoener C, Lochner S, Lindenberger D. European natural gas infrastructure: the impact of market developments on gas flows and physical market integration. Appl Energy. 2013;102:994-1003.

19. Chaudry M, Jenkins N, Qadrdan M, Wu JZ. Combined gas and electricity network expansion planning. Appl Energy. 2014;113:1171-87.

20. Chiang N-Y, Zavala VM. Large-scale optimal control of interconnected natural gas and electrical transmission systems. Appl Energy. 2016;168:226-35

21. Rimkevicius S, Kaliatka A, Valincius M, Dundulis G, Janulionis R, Grybenas A, et al. Development of approach for reliability assessment of pipeline network systems. Appl Energy. 2012;94:22-33.

22. Su H, Zhang J, Zio E, Yang N, Li X, Zhang Z. An integrated systemic method for supply reliability assessment of natural gas pipeline networks. Appl Energy. 2018;209:489-501.

23. Lu W, Su M, Fath BD, Zhang M, Hao Y. A systematic method of evaluation of the Chinese natural gas supply security. Appl Energy. 2016;165:858-67.

24. Zhang Q, Li Z, Wang G, Li H. Study on the impacts of natural gas supply cost on gas flow and infrastructure deployment in China. Appl Energy. 2016:162:1385-98.

25. BP. Statistical Review of World Energy. 2017

26. Aguilera RF. The role of natural gas in a low carbon Asia Pacific. Appl Energy. 2014;113:1795-800

27. National Bureau of Statistic of China. China energy statistical yearbook Beijing: China statistics press; 2016.

28. National Development and reform commission. 2017 Gas operations profile. 2018.

29. National Development and reform commission. The 13th-five-year plan of energy development. 2016 
30. Li J, Dong X, Shangguan J, Hook M. Forecasting the growth of China's natural gas consumption. Energy. 2011;36(3):1380-5.

31. Zeng B, Li C. Forecasting the natural gas demand in China using a selfadapting intelligent grey model. Energy. 2016;112:810-25.

32. Shaikh F, Ji Q, Shaikh PH, Mirjat NH, Uqaili MA. Forecasting China's natural gas demand based on optimised nonlinear grey models. Energy. 2017;140:941-51.

33. Zhang W, Yang J. Forecasting natural gas consumption in China by Bayesian model averaging. Energy Rep. 2015;1:216-20.

34. Shaikh F, Ji Q. Forecasting natural gas demand in China: logistic modelling analysis. Int J Elec Power. 2016;77:25-32.

35. Sinopec. Relevant information on the opening up of Sinopec Oil \& Gas Pipeline Network facilities. 2017.

36. CNPC. Natural gas pipeline transportation costs related information. 2017.

37. CNOOC. Announcement on Gas Equipment Group Gas Information Disclosure. 2017.

38. Corporation GD. GAMS—A user's guide. 2008

\section{Publisher's Note}

Springer Nature remains neutral with regard to jurisdictional claims in published maps and institutional affiliations.

Ready to submit your research? Choose BMC and benefit from:

- fast, convenient online submission

- thorough peer review by experienced researchers in your field

- rapid publication on acceptance

- support for research data, including large and complex data types

- gold Open Access which fosters wider collaboration and increased citations

- maximum visibility for your research: over $100 \mathrm{M}$ website views per year

At BMC, research is always in progress.

Learn more biomedcentral.com/submissions 